\title{
Strategi Pemasaran Jasa Pendidikan dalam Upaya Meningkatkan Citra Madrasah Swasta (Studi Kasus di MTs Sudirman Jatisrono, Wonogiri)
}

\author{
Eka Yuni Purwanti, S.Pd.I, M.Pd, Ririn Nuraini, M.Pd \\ Sekolah Tinggi Agama Islam Mulia Astuti Wonogiri, Institut Agama Islam Riyadlotul Mujahidin \\ Ngabar Ponorogo \\ ekayunipurwanti.alhaidari@gmail.com, ririnnuraini453@gmail.com
}

\section{Abstract}

This research is motivated by the fact that in this globalization era there are a lot of competitions in the world of education. The large number of public school makes private schools underestimated by the community. The competition between schools and madrasahs are increasing rapidly due to how the marketing strategies are implemented. So this research is to determine: How is the marketing strategy of educational services at MTs Sudirman Jatisrono, Wonogiri; How is the implementation of the marketing mix strategy for educational services to improve the image of MTs Sudirman Jatisrono, Wonogiri; How is the public response of the implementation of marketing mix strategy for educational service to improve the image of MTs Sudirman Jatisrono, Wonogiri.This research is qualitative research. Based on the data findings, MTs Sudirman Jatisrono, Wonogiri carried out three things which form the basis of marketing strategy. First, Segmentation (Market Segmentation); Targeting (Establishing Target Markets); Positioning (Determining Market Position). Second, there are seven elements that are very concerned by MTs Sudirman Jatisrono Wonogiri in order to achieve the expected goals 
namely : Product, the products provided various of intracurricular and extra- curricular activities as well as providing good services for the users. Price, the cost offered is very affordable by all level of society. Place/ Location is located near the highway and the road is accessible. Promotion, it is carried out through various media and activities. People / Participant are professional teaching staff and based on their fields. Physical Evidence (physical facilities), providing buildings and infrastructure to distribute service. Process, this carried out with various methods and strategies. Third, a good relationship will create a good image, so the marketing mix will get a positive response from the society. Many factors are influencing the service users, both of prospective students and the society. Some are according to internal desires and external desires. From socio- cultural and psychological factors, those will be able to influence prospective service users or prospective students who will enter to MTs Sudirman Jatisrono, Wonogiri.

\section{Abstrak}

Penelitian ini dilatarbelakangi oleh kenyataan bahwa di era globalisasi saat ini banyak sekali persaingan dalam dunia pendidikan. Banyaknya sekolah negeri membuat sekolah swasta dipandang sebelah mata oleh masyarakat. Persaingan antara sekolah dan madrasah meningkat pesat karena bagaimana strategi pemasaran diterapkan. Maka penelitian ini bertujuan untuk mengetahui: Bagaimana strategi pemasaran jasa pendidikan di MTs Sudirman Jatisrono Wonogiri; Bagaimana implementasi strategi bauran pemasaran jasa pendidikan untuk meningkatkan citra MTs Sudirman Jatisrono, Wonogiri; Bagaimana tanggapan masyarakat terhadap penerapan strategi bauran pemasaran jasa pendidikan dalam meningkatkan citra MTs Sudirman Jatisrono Wonogiri. 
Penelitian ini merupakan penelitian kualitatif. Berdasarkan data temuan, MTs Sudirman Jatisrono Wonogiri melakukan tiga hal yang menjadi dasar strategi pemasaran. Pertama, Segmentasi (Segmentasi Pasar); Targeting (Menetapkan Pasar Sasaran); Positioning (Menentukan Posisi Pasar). Kedua, ada tujuh unsur yang sangat diperhatikan oleh MTs Sudirman Jatisrono Wonogiri guna mencapai tujuan yang diharapkan yaitu: Produk, produk yang disediakan berbagai kegiatan intrakurikuler dan ekstrakurikuler serta memberikan pelayanan yang baik bagi penggunanya. Harga, biaya yang ditawarkan sangat terjangkau oleh semua lapisan masyarakat. Tempat / Lokasi terletak di dekat jalan raya dan jalan dapat diakses. Promosi, dilakukan melalui berbagai media dan kegiatan. Orang / Peserta adalah tenaga pengajar yang profesional dan sesuai dengan bidangnya. Bukti Fisik (sarana fisik), penyediaan gedung dan infrastruktur untuk mendistribusikan pelayanan. Prosesnya, ini dilakukan dengan berbagai metode dan strategi. Ketiga, hubungan yang baik akan menciptakan citra yang baik, sehingga bauran pemasaran akan mendapat respon yang positif dari masyarakat. Banyak faktor yang mempengaruhi pengguna jasa, baik calon mahasiswa maupun masyarakat. Beberapa sesuai dengan keinginan internal dan keinginan eksternal. Dari faktor sosial budaya dan psikologis tersebut nantinya dapat mempengaruhi calon pengguna jasa atau calon siswa yang akan masuk ke MTs Sudirman Jatisrono, Wonogiri.

Keywords: Madrasah Image, Service Marketing Strategy.

\section{A. Pendahuluan}

Berkembangnya zaman kini telah masuk pada era globalisasi yang melanda Indonesia secara cepat membuka cakrawala baru bagi manajemen perusahaan-perusahaan Indonesia, yang semula hanya tertuju ke lingkungan domestik, menjadi terbuka ke lingkungan global. Tiba-tiba 
manajemen perusahaan di Indonesia dipaksa untuk mengikuti olimpiade dalam menghasilkan produk dan jasa, dengan mengikuti peraturan-peraturan tingkat dunia dalam menyediakan produk dan jasa tersebut bagi masyarakat. Keadaan ini memaksa perusahaan yang ada di Indonesia untuk melakukan rekayasa ulang terhadap strategi yang selama ini digunakan untuk menghasilkan produk dan jasa.

Masa seperti ini dapat dikatakan proses pembangunan yang semakin berkembangnya pertumbuhan ekonomi dan industri di Indonesia, karena telah banyak mengalami kemajuan yang sangat pesat dibandingkan dengan masamasa sebelumnya. Hal ini dapat dilihat dari semakin banyaknya produsen yang terlibat dalam memenuhi keinginan konsumen sehingga menyebabkan setiap perusahaan harus menempatkan orientasi pada kepuasan konsumen sebagai tujuan utama. Perusahaan harus dapat memberikan kepada pelanggan barang atau jasa yang mempunyai nilai lebih tinggi, dengan mutu lebih baik, harga lebih terjangkau, fasilitas yang memadai dan pelayanan yang lebih baik dari pada pesaing lainnya.

Dalam menghadapi pesaing dari berbagai sudut, suatu perusahaan atau lembaga mempunyai organisasi yang digunakan untuk menangkis keterbelakangan pada perkembangan perusahaan atau lembaga. Seperti perusahaan jasa yang menggunakan berbagai strategi guna mencapai tujuan yaitu memuaskan konsumen dan mendapatkan citra yang baik dari konsumen.

Lembaga pendidikan adalah sebuah kegiatan yang melayani konsumen berupa siswa dan masyarakat umum yang dikenal sebagai stakeholder. Lembaga pendidikan pada hakikatnya bertujuan untuk memberikan layanan dan pihak yang dilayani ingin memperoleh kepuasan dari layanan tersebut, karena mereka sudah membayar cukup mahal 
kepada lembaga pendidikan. Namun, pendidikan di sini diartikan bukan sebagai organisasi bisnis melainkan pendidikan tergolong dalam marketing jasa yang "non profit oriented" atau perusahaan nirlaba. Di mana lembaga pendidikan tidak mencari keuntungan semata, akan tetapi demi kemakmuran para pengurus atau pemilik lembaga. Keuntungan ini tujuannya untuk meningkatkan mutu layanan kepada masyarakat atau stakeholder dan sebagai upaya untuk meningkatkan citra lembaga, serta meningkatkan calon atau jumlah siswa yang berminat mendaftarkan diri di lembaga pendidikan tersebut.

Perusahaan nirlaba ada pada sekolah umum dan madrasah. Sesuai dengan peraturan Menteri Agama RI No. 1 tahun 1946 dan preaturan Mentri Agama RI No. 7 tahun 1950, madrasah adalah tempat pendidikan yang diatur sebagai sekolah dan membuat pendidikan dan ilmu pengetahuan agama, menjadi pokok pengajaran. Definisi lain dari madrasah adalah lembaga pendidikan yang menjadikan mata pelajaran agama Islam sebagai dasar yang diberikan sekurang-kurangnya $30 \%$ di samping mata pelajaran umum. ${ }^{1}$

Masyarakat lebih banyak mengenal sekolah umum daripada madrasah, sehingga memasukkan anak-anak mereka ke sekolah umum yang sudah berstatus Negeri. Sedangkan madrasah yang masih swasta seperti MI, MTs, dan MA sederajat hanya dipandang sebelah mata oleh masyarakat. Madrasah dijadikan sekolah ke dua setelah memilih pada sekolah umum Negeri, sehingga banyak madrasah yang kekurangan siswa atau jumlahnya lebih sedikit pada saat penerimaan siswa baru.

${ }^{1}$ Haidar Purta Daulay, Pendidikan Islam dalam Sistem Pendidikan Nasional di Indonesia, (Jakarta: Prenada Media, 2004), 56-57. 
Masalah seperti ini mendorong sebuah madrasah untuk memfungsikan bagian humas agar mengkonsep sesempurna mungkin strategi-strategi pemasaran jasa pendidikan kepada masyarakat, supaya madrasah dipandang sama pentingnya dengan pendidikan di lembaga-lembaga lainnya. Oleh karena itu, madrasah harus berfokus pada strategi pemasaran untuk memasarkan jasa pendidikan dalam upaya memberi layanan yang menjadikan kepuasan bagi konsumen.

Kenneth R. Andrews menyatakan bahwa strategi adalah pola keputusan dalam perusahaan yang menentukan dan mengungkapkan sasaran, maksud atau tujuan yang menghasilkan kebijaksanaan utama dan merencanakan untuk mencapai tujuan serta merinci jangkauan bisnis yang akan dikejar oleh perusahaan. ${ }^{2}$

Pemasaran dapat didefinisikan sebagai suatu proses dalam menentukan permintaan konsumen akan barang dan jasa, memotivasi penjualan, mendistribusikan ke konsumen akhir, dengan keuntungan sebagai imbalannya. Jadi strategi pemasaran menurut Bygrave adalah kumpulan petunjuk dan kebijakan yang digunakan secara efektif untuk mencocokkan program pemasaran (produk, promosi, harga, dan distribusi) dengan peluang pasar guna mencapai sasaran usaha. ${ }^{3}$

Sekolah atau madrasah bukanlah perusahaan yang dapat menghasilkan barang, akan tetapi produksi dari sekolah atau madrasah adalah jasa atau layanan pendidikan. Jadi penting sekali adanya strategi pemasaran bagi sekolah maupun madrasah. Pemasaran jasa pendidikan berarti kegiatan lembaga pendidikan memberi layanan atau

2 Buchari Alma, Manajemen Pemasaran dan Pemasaran Jasa, (Bandung: Alfabeta, 2007), 199.

${ }^{3}$ M. Ismail Yusanto dan M. Karebet W., Menggagas Bisnis Islam, (Jakarta: Gema Insani, 2002), 169. 
menyampaikan jasa pendidikan kepada konsumen dengan cara yang memuaskan.

Apabila lulusan dan jasa pendidikan yang dihasilkan sesuai dengan keinginan masyarakat, maka masyarakat akan memandang citra lembaga tersebut baik. Karena citra mempunyai pengaruh penting bagi manajemen, dengan kata lain citra mempunyai dampak internal bagi lembaga, karena citra yang positif maupun negatif sangat berpengaruh terhadap kinerja karyawan. Citra merupakan realitas, oleh karena itu jika komunikasi pasar tidak cocok dengan realitas, ketidakpuasan akan muncul dan akhirnya konsumen mempunyai persepsi yang buruk terhadap citra organisasi. ${ }^{4}$

Citra suatu lembaga akan terbentuk dari bagaimana lembaga tersebut menjalankan seluruh kegiatannya. Dengan adanya manajemen pemasaran jasa pendidikan yang dilakukan oleh suatu lembaga akan menarik perhatian masyarakat untuk menoleh ke arah lembaga tersebut. Sehingga akan memunculkan sebuah citra lembaga, dan pada akhirnya masyarakat berpartisipasi dalam kegiatan lembaga, serta mengakui pentingnya pendidikan Islam yang ada pada sebuah madrasah.

MTs Sudirman Jatisrono, Wonogiri, merupakan sekolah yang menyajikan pendidikan umum dan pendidikan agama Islam sebagai sebuah program yang integratif. Lembaga ini masih di bawah naungan Kementrian Agama atau biasa disebut dengan lembaga swasta, sehingga tidak heran jika siswa yang masuk lebih sedikit dibandingkan sekolah Negeri. Sehingga untuk menghadapi persaingan, berbagai pemasaran dilakukan untuk mencapai tujuan tertentu. Oleh karena itu, MTs Sudirman Jatosrono, Wonogiri membutuhkan suatu strategi yang sesuai dengan

4 Sutisna, Perilaku Konsumen dan Komunikasi Pemasaran, (Bandung: PT. Remaja Rosdakarya, 2003), 332-333. 
apa yang ingin dicapai. Melalui strategi bauran pemasaran (marketing mix) jasa pendidikan, lembaga ini tidak lagi hanya dipandang sebelah mata oleh masyarakat, sehingga banyak siswa yang masuk di sana. Dengan memberikan pelayanan yang baik bagi pengguna jasa (siswa maupun masyarakat) berarti memberikan kepuasan kepada mereka, sehingga akan menjadikan citra yang baik pula untuk MTs.

Berdasarkan latar belakang yang telah dipaparkan, betapa pentingnya strategi pemasaran jasa pendidikan di sebuah lembaga swasta untuk menghadapi persaingan globalisasi, sehingga peneliti mengadakan penelitian tentang strategi pemasaran jasa pendidikan dengan judul "Strategi Pemasaran Jasa Pendidikan dalam Upaya Meningkatkan Citra Madrasah Swasta (Studi Kasus di MTs Sudirman Jatisrono, Wonogiri)."

\section{B. Strategi Pemasaran Jasa Pendidikan di MTs Sudirman Jatisrono, Wonogiri}

Setelah penulis mengumpulkan data-data yang diperoleh dari penelitian melalui metode wawancara, observasi maupun dokumentasi, maka penulis telah mendeskripsikan data sesuai hasil penelitian sehingga menghasilkan temuan-temuan penelitian di bawah ini.

Sekolah atau Madrasah membutuhkan strategi dalam pemasaran. Strategi adalah cara mencapai tujuan yang sudah ditetapkan, sedangkan pemasaran merupakan suatu cara yang dilakukan sekolah untuk memperkenalkan sekolah kepada masyarakat atau memperkenalkan produk kepada masyarakat. Dengan cara memperkenalkan kepada masyarakat itulah sekolah bisa mendapatkan kepercayaan dari masyarakat. Ini sesuai dengan pernyataan M. Ismail Yusanto dan M. Karebet W, tentang strategi pemasaran menurut Bygrave adalah kumpulan petunjuk dan kebijakan 
yang digunakan secara efektif untuk mencocokkan program pemasaran (produk, promosi, harga, dan distribusi) dengan peluang pasar guna mencapai sasaran usaha. ${ }^{5}$

MTs Sudirman Jatisrono, Wonogiri memperhatikan tiga konsep sebagai dasar strategi pemasaran jasa pendidikan, yaitu Segmentation (Segmentasi Pasar), Targeting (Menetapkan Pasar Sasaran), dan Positioning (Menentukan Posisi Pasar). Sesuai dengan teori Desi Trisnawati, secara garis besar suatu perusahaan memerlukan strategi pemasaran untuk meraih keunggulan dengan tiga kegiatan, yaitu Segmentation (Segmentasi Pasar), Targeting (Menetapkan Pasar Sasaran), dan Positioning (Menentukan Posisi Pasar). ${ }^{6}$

1. Segmentation (Segmentasi Pasar)

Dampak dari mobilitas yang tinggi dan kurangnya pantauan dari orang tua menyebabkan perkembangan anak mereka mudah terpengaruh dengan budaya modern yang kurang sejalan dengan budaya masyarakat Jatisrono. Masyarakat berharap akan adanya sekolah Islam, agar anak-anak mereka tidak terpengaruh dengan budaya modern yang tidak baik. Dengan adanya MTs Sudirman Jatisrono, Wonogiri ini, masyarakat memiliki kepercayaan kelak anak mereka mempunyai pendidikan agama Islam yang baik dan memiliki perilaku yang baik pula.

Adanya peluang untuk mendirikan sebuah lembaga pendidikan Islam, MTs Sudirman Jatisrono, Wonogiri terlebih dahulu mengidentifikasi terhadap peluangpeluang yang muncul. Dengan tanggapan yang positif dari masyarakat, maka MTs Sudirman Jatisrono,

${ }^{5}$ Yusanto dan Karebet W., Menggagas Bisnis Islam, 169.

${ }^{6}$ Desi Trisnawati, "Konsep Pemasaran Dalam Perspektif Syariah," Cakrawala, 2 (Desember, 2007), 116-119. 
Wonogiri beranggapan bahwa kegiatan segmentasi ini bertujuan untuk mempermudah pemasaran, yaitu dengan menaiknya calon siswa yang mendaftarkan diri ke MTs Sudirman Jatisrono, Wonogiri. Hal ini diungkapkan oleh Ali Hasan, bahwa kegiatan segmentasi bertujuan agar mempermudah pemasaran yaitu penetrasi pasar yang biasa digunakan untuk menaikan jumlah penjualan. ${ }^{7}$

Oleh karena itu, segmentasi dilakukan oleh pihak MTs Sudirman Jatisrono, Wonogiri sebagai penentu siapa kelak calon siswa yang akan mendaftarkan di sana. Sudah jelas bahwa adanya peluang besar ini digunakan sebagai dasar untuk berdirinya MTs Sudirman Jatisrono, Wonogiri.

2. Targeting (Menetapkan Pasar Sasaran)

Banyaknya sekolah negeri maupun swasta yang hanya menyajikan pendidikan umum, menjadi salah satu faktor pendukung untuk menyediakan sebuah pendidikan Islam yang dapat mewarnai pendidikan di sekitar Jatisrono. Mayoritas penduduk di sekitar MTs Sudirman Jatisrono, Wonogiri adalah Muslim, akan tetapi sangat minim dalam pendidikan Islam karena kebanyakan dari mereka merupakan pedagang. Sehingga tidak heran jika anak-anak mereka kurang mendapat perhatian dalam hal pendidikan Islam.

Walaupun banyak masyarakat sekitar yang berdagang, namun tidak sedikti pula yang pekerjaannya adalah petani. Sehingga MTs Sudirman Jatisrono, Wonogiri ingin menyediakan pendidikan yang banyak agama Islamnya kepada semua lapisan masyarakat, baik yang keadaan ekonominya menengah ke bawah maupun

${ }^{7}$ Hasan, Marketing Bank Syariah, 125-127. 
yang menengah ke atas, bisa bersekolah di MTs Sudirman Jatisrono, Wonogiri.

Hal ini berkaitan dengan teori Nur Riyanto Al-Arif yang menyatakan bahwa ada kriteria yang harus diperhatikan: ${ }^{8}$

a) Suatu perusahaan atau lembaga harus memastikan segmen yang akan dibidik cukup besar dan menguntungkan atau berpeluang besar.

b) Strategi targeting harus berdasarkan pada keunggulan kompetitif perusahaan atau lembaga yang bersangkutan.

c) Segmen pasar yang dibidik harus didasarkan pada situasi persaingan

Dapat ditarik kesimpulan bahwa MTs Sudirman Jatisrono, Wonogiri melakukan targeting sesuai dengan ketiga kriteria di atas, yaitu banyak masyarakat dari berbagai lapisan baik menengah ke bawah maupun menengah ke atas yang dapat bersekolah di MTs Sudirman Jatisrono, Wonogiri. Mayoritas pendudukanya adalah muslim, sehingga terdapat kesesuaian dengan adanya sekolah yang bernaungan agama Islam. Dan MTs Sudirman Jatisrono, Wonogiri memilih pendidikan dalam persaingan.

3. Positioning (Menentukan Posisi Pasar)

MTs Sudirmaan Jatisrono, Wonogiri menentukan posisi di antara lima Kecamatan, yaitu Jatiroto, Jatisrono, Jatipurno, Girimarto, dan Sidoharjo. Yang mana Jatisrono merupakan kecamatan yang berada di tengah-tengah, sehingga pendiriannya ditetapkan di Jatisrono. Selain itu, Jatisrono juga menjadi kecamatan yang paling banyak penduduknya, paling maju perekonomiannya dan

${ }^{8}$ Riyanto Al-Arif, Dasar-dasar Pemasaran Bank Syariah, 95-56. 
dianggap sebagai pusat dari lima kecamatan itu. Jadi posisi ini menjadikan pilihan yang baik untuk menetapkan pembangunan lembaga pendidikan yang bernuansa Islam, dan mempunyai tujuan supaya masyarakat memiliki kepercayaan dan memasukkan anak-anak mereka ke MTs Sudirman Jatisrono, Wonogiri.

Penentuan posisi pasar MTs Sudirman Jatisrono, Wonogiri sesuai dengan Nur Riyanto Al-Arif yang mengatakan bahwa Penentuan posisi pasar ini bertujuan untuk membangun kepercayaan, keyakinan, dan kompetisi bagi konsumen. Dengan adanya positioning akan tercipta perbedaan, keuntungan, dan manfaat yang membuat konsumen selalu ingat dengan produk atau jasa yang diberikan. ${ }^{9}$

Oleh karena itu, pelayanan baik yang diberikan oleh MTs Sudirman Jatisrono, Wonogiri menjadi pembangun kepercayaan masyarakat terhadap MTs Sudirman Jatisrono, Wonogiri.

\section{Pelaksanaan Bauran Pemasaran (Marketing Mix) Jasa} Pendidikan dalam Upaya Meningkatkan Citra Madrasah Swasta di MTs Sudirman Jatisrono, Wonogiri

MTs Sudirman Jatisrono, Wonogiri menggunakan berbagai strategi dengan memadukan beberapa kegiatan agar tujuan yang telah ditentukan dapat tercapai. Pemasaran jasa pendidikan yang menggunakan beberapa strategi yang memadukan beberapa kegiatan dan dikemas secara baik, akan menghasilkan pemasaran yang baik pula, serta memberi kepuasan kepada pengguna jasa dan mendapat citra yang baik dari masyarakat.

\footnotetext{
${ }^{9}$ Ibid.
} 
Ada tujuh unsur yang sangat diperhatikan oleh MTs Sudirman Jatisrono, Wonogiri guna mencapai tujuan yang diharapkan, yaitu product (produk), price (harga), place (tempat/lokasi), promotion (promosi), people (orang/pertisipan), physical Evidence (sarana fisik), dan process (proses). Yang dilakukan dengan membaur yang biasa disebut bauran pemasaran.

Hal ini sesuai dengan teori yang dikemukakan oleh Buchari Alma tentang bauran pemasaran. Menurutnya, bauran pemasaran (marketing mix) merupakan unsur-unsur pemasaran yang saling terkait, dibaurkan, diorganisirkan dan digunakan dengan tepat, sehingga perusahaan dapat mencapai tujuan pemasaran yang efektif, sehingga dapat memuaskan konsumen. Unsur-unsur yang saling berkaitan dalam bauran pemasaran (marketing mix), yaitu product (produk), price (harga), place (tempat/lokasi), promotion (promosi), people (orang/pertisipan), physical Evidence (sarana fisik), dan process (proses). ${ }^{10}$

1. Product (produk)

Produk yang diberikan oleh MTs Sudirman Jatisrono, Wonogiri adalah berbagai kegiatan intra kurikuler seperti pelajaran keagamaan Bahasa Arab, Sejarah Kebudayaan Islam (SKI), Al-Qur'an dan Hadits, Akidah Akhlak, dan Fiqih, dan Organisasi Siswa Intra Sekolah (OSIS), serta kegiatan ekstra kurikuler secara umum disetiap sekolah setingkat MTs ada ekstra kurikuler pramuka dan PMR serta ekstra unggulan sekolah yang lain. MTs Sudirman Jatisrono, Wonogiri ini selain pramuka dan PMR, juga menyediakan ekstra kurikuler Drumband, Hadroh/Rebana, Qiro'ah, keislaman dan menjahit.

${ }^{10}$ Alma, et al., Manajemen Corporate dan Strategi Pemasaran Jasa Pendidikan, 154. 


\section{Price (harga)}

Harga yang ditawarkan oleh MTs Sudirman Jatisrono sangatlah terjangkau masyarakat sekitar. Tiap bulan hanya Rp. 50.000 saja dengan memberikan pelayanan yang baik kepada siswa. Sehingga dari masyarakat yang perekonomiannya menengah ke bawah bisa memasukan anak-anak mereka ke MTs Sudirman Jatisrono. Dengan adanya harga yang terjangkau dari semua lapisan masyarakat, ini menjadi salah satu faktor yang dapat mempengaruhi masyarakat agar memilih memasukkan anak-anak mereka ke MTs Sudirman Jatisrono, Wonogiri.

Biaya Rp. 50.000 sudah cukup untuk membiayai pendidikan di MTs Sudirman Jatisrono, Wonogiri. Harga memang akan menimbulkan persepsi mengenai kualitas dan layanan, sehingga dengan harga yang ditawarkan kepada pengguna jasa harus memperhatikan dan meningkatkan kualitas dan layanan agar terjadi keseimbangan antara keduanya. Biaya yang dibebankan kepada siswa sudah mencukupi untuk operasional sekolah, dan diringankan juga dengan adanya BOS.

3. Place (tempat/lokasi)

Letak yang strategis, mudah dijangkau, dan jauh dari keramaian adalah tempat yang dicari masyarakat untuk menempatkan anak mereka agar mendapat ketenangan pada saat belajar. MTs Sudirman Jatisrono, Wonogiri memang mudah ditemukan, karena tidak jauh dari jalur utama jalan raya Ponorogo-Solo dan berada di tengah-tengah kecamatan Jatisrono.

4. Promotion (promosi)

Dengan adanya kegiatan seperti yang telah diungkapkan di atas, ini merupakan sebagian promosi yang bertujuan untuk mendapatkan perhatian dari 
masyarakat sehingga nantinya masyarakat tertarik untuk memasukkan anak-anaknya ke MTs Sudirman Jatisrono, Wonogiri. Tidak hanya lewat radio, brosur dan kegiatan, melainkan pihak Madrasah bekerja sama dengan para Ulama di sekitarnya untuk ikut mempromosikan kepada masyarakat pada saat pengajian.

5. People (orang/pertisipan)

Para guru di sana ada yang sudah PNS dan ada juga yang belum PNS, tetapi sudah bersertifikasi sesuai bidang masing-masing. Tenaga pendidikan dan kependidikan di MTs Sudirman Jatisrono, Wonogiri berjumlah 25 guru dan karyawan, yang terdiri dari 19 guru S1, 2 guru D3, dan 1 guru D2. Sedangkan tenaga Tata Usaha terdiri dari 2 karyawan lulusan SMA dan 1 karyawan yang S1. Selain lulusan SI dari perguruan tinggi umum, MTs Sudirman Jatisrono, Wonogiri juga melengkapi pendidik profesional yang berasal dari beberapa pondok pesantren.

6. Physical Evidence (sarana fisik)

Fasilitas pendidikan yang disediakan untuk para siswa, mengikuti perkembangan dalam pendidikan. Seperti gedung yang digunakan sebagai tempat berinteraksi antara penyedia jasa dan pengguna jasa, sehingga ruang kelas dilengkapi dengan LCD agar penyampaian materi semakin mudah disampaikan dan diterima. Adanya ruangan LAB dan seragam para guru maupun siswa yang baik menjadi bukti fisik.

7. Process (proses)

Pendidik menyampaikan materi dengan berbagai metode dan sebagian menggunakan LCD. Proses yang baik akan memberi kepuasan kepada siswa, sehingga pembelajaran dapat berjalan dengan baik dan siswa pun dapat menerima semua materi yang disampaikan oleh guru. 
Dapat disimpulkan bahwa MTs Sudirman Jatisrono, Wonogiri menggunakan strategi pemasaran jasa pendidikan dengan bauran pemasaran (Marketing Mix), agar dapat memberi kepuasan pada pengguna jasa baik siswa maupun masyarakat, sehingga dapat meningkatkan citra Madrasah swasta MTs Sudirman Jatisrono, Wonogiri.

\section{Tanggapan Masyarakat terhadap Pelaksanaan Bauran Pemasaran (Marketing Mix) Jasa Pendidikan dalam Upaya Meningkatkan Citra Madrasah Swasta di MTs Sudirman Jatisrono, Wonogiri}

Kepercayaan dari masyarakat terhadap MTs Sudirman Jatisrono, Wonogiri menjadikah suatu kekuatan untuk terus berkembang. Hubungan yang baik akan menumbuhkan citra yang baik pula, sehingga dengan adanya bauran pemasaran yang dilakukan, mendapatkan respon positif dari masyarakat. Dengan mencetak lulusan yang mempunyai nilai baik serta memiliki keahlian yang menjadi keunggulan MTs Sudirman Jatisrono, Wonogiri, masyarakat akan memberikan kepercayaan, sehingga akan terbentuk citra yang baik.

Banyak faktor yang mempengaruhi pengguna jasa baik calon siswa maupun masyarakat. Misalnya seorang anak yang mau mendaftarkan di MTs Sudirman Jatisrono, Wonogiri, ternyata teman-temannya mendaftarkan ke sekolah negeri pasti anak tersebut akan ikut dengan temantemannya mendaftar ke sekolah negeri. Begitu pula dengan orang tuanya yang mengikuti kebanyakan masyarakat memilih sekolah untuk anak-anak mereka. Akan tetapi tidak sedikit calon siswa yang mempunyai keinginan sendiri untuk mendaftar di MTs Sudirman Jatisrono, Wonogiri. Jadi faktor sosial budaya dan faktor psikologis mempunyai pemgaruh yang sangat besar terhadap keputusan penentuan sekolah. 
Dari bukti-bukti di atas, sejalan dengan teori dari A. A. Anwar Prabu Mangkunegara yang menyatakan bahwa keberhasilan dalam mencapai citra yang baik tidak lepas dari beberapa faktor yang mempengaruhi perilaku konsumen. yaitu: ${ }^{11}$

Faktor-faktor yang mempengaruhi perilaku konsumen,

1. Kekuatan sosial budaya
a) Faktor budaya
b) Faktor kelas sosial
c) Faktor kelompok anutan (Small Reference Group)
d) Faktor keluarga

2. Kekuatan faktor psikologis

a) Faktor pengalaman belajar

b) Faktor kepribadian

c) Faktor sikap dan keyakinan

d) Konsep diri (self concept)

Dari pembahasan di atas, dapat disimpulkan bahwa banyak faktor dari sosial budaya dan psikologis yang dapat mempengaruhi calon pengguna jasa atau calon siswa yang akan masuk ke MTs Sudirman Jatisrono, Wonogiri.

\section{E. Kesimpulan}

MTs Sudirman Jatisrono, Wonogiri melaksanakan tiga hal yang menjadi dasar strategi pemasaran, yaitu: Segmentation (Segmentasi Pasar), mengidentifikasi terhadap peluang-peluang yang muncul dan mendapat tanggapan yang positif dari masyarakat untuk mendirikan pendidikan Islam. Targeting (Menetapkan Pasar Sasaran), menyediakan pendidikan yang banyak agama Islamnya kepada semua lapisan masyarakat. Positioning (Menentukan Posisi Pasar), menentukan tempat yang paling banyak penduduknya,

\footnotetext{
${ }^{11}$ Prabu Mangkunegara, Perilaku Konsumen, 39-48.
} 
paling maju perekonomiannya dan mayoritas beragama Islam.

Ada tujuh unsur yang sangat diperhatikan oleh MTs Sudirman Jatisrono, Wonogiri guna mencapai tujuan yang diharapkan, yaitu : Product (produk), produk yang diberikan adalah berbagai kegiatan intra kurikuler dan kegiatan ekstra kurikuler serta memberi pelayanan yang baik bagi pengguna jasa. Price (harga), biaya yang ditawarkan sangat terjangkau oleh semua lapisan masyarakat. Place (tempat/lokasi) letaknya dekat jalan raya dan jalannya mudah diakses. Promotion (promosi), promosi dilakukan melalui berbagai media dan kegiatan. People (orang/pertisipan) tenaga pendidik yang propesional dan sesuai bidangnya. Physical Evidence (sarana fisik), menyediakan gedung dan sarana prasarana untuk menyalurkan jasa. Process (proses), proses dilaksanakan dengan metode dan strategi yang bervariasi.

Hubungan yang baik akan menumbuhkan citra yang baik pula, sehingga dengan adanya bauran pemasaran (marketing mix) yang dilakukan, mendapatkan respon positif dari masyarakat. Banyak faktor yang mempengaruhi pengguna jasa baik calon siswa maupun masyarakat. Ada yang menurut keinginan internal dan ada pula yang menurut keinginan eksternal. Dari beberapa faktor sosial budaya dan psikologis, maka dapat mempengaruhi calon pengguna jasa atau calon siswa yang akan masuk ke MTs Sudirman Jatisrono, Wonogiri.

\section{Referensi}

Al-Arif, Riyanto. Dasar-dasar Pemasaran Bank Syariah. Bandung: Alfabeta, 2010.

Alma, Buchari et al. Manajemen Corporate dan Strategi Pemasaran Jasa Pendidikan. Bandung: Alfabeta, 2008. 
Alma, Buchari. Manajemen Pemasaran dan Pemasaran Jasa. Bandung: Alfabeta, 2007.

Arikunto, Suharsimi. Manajemen Penelitian. Jakarta: Rineka Cipta, 2000.

Basrowi dan Suwandi. Memahami Penelitian Kuantitatif. Jakarta: Rineka Cipta, 2008.

Daulay, Haidar Purta. Pendidikan Islam dalam Sistem Pendidikan Nasional di Indonesia. Jakarta: Prenada Media, 2004.

Emzir. Metodologi Penelitian Kualitatif: Analisis Data. Jakarta: PT. Raja Grafindo Persada, 2010.

Hasan, Marketing Bank Syariah. Bogor: Ghalia Indonesia, 2010.

Mangkunegara, A. A. Anwar Prabu. Perilaku Konsumen. Bandung: PT. Refika Aditama, 2002.

Moleong, Lexy. Metodologi Penelitian Data Kualitatif. Bandung: PT. Remaja Rosdakarya, 2001.

Sutisna. Perilaku Konsumen dan Komunikasi Pemasaran.

Bandung: PT. Remaja Rosdakarya, 2003.

Trisnawati, Desi "Konsep Pemasaran Dalam Perspektif Syariah" Jurnal Cakrawala. Desember, 2007.

Yusanto, M. Ismail dan M. Karebet W. Menggagas Bisnis Islam. Jakarta: Gema Insani, 2002. 